\title{
El Sufragio Universal puesto a consideración. El Sexenio Democrático y la Restauración, dos etapas para el análisis
}

\section{GLORIA ESPIGADO TOCINO}

Pasado el Sexenio Revolucionario, que supone para este país el primer ensayo democrático en la designación de la representación política de la nación, la Restauración borbónica, a comienzos de 1891, retoma, no sin ciertos ajustes, la práctica electoral de entonces.

El interés por descubrir las similitudes y las divergencias en la conducción de los comicios correspondientes a estas etapas históricas no está exento del prejuicio previo del que partimos la mayoría de los historiadores al considerar modélicos, en libertad y legalidad, los procesos electorales abiertos a partir de La Gloriosa, especialmente las consultas que fueron realizadas bajo la moralidad y escrupulosidad sistemáticamente atribuidas a los responsables de la República de 1873, mientras que, por el contrario, el alcance del sufragio restauracionista se mide siempre desde la perspectiva de la manipulación del voto y el fraude electoral, no en vano caciquismo, encasillado, embolado, etc... son expresiones que han pasado a caracterizar el largo período borbónico que va de 1875 a 1931.

La propuesta que aquí hacemos y que justifica las páginas que presentamos a este Congreso intenta una sana, a nuestro juicio, desvinculación de todo presupuesto apriorístico, profundizando y descubriendo en un sujeto de estudio concreto, las convocatorias de mayo de 1873 y enero de 1891 celebradas en Cádiz, los entresijos que rodean la expresión política máxima del sistema demoliberal implantado, esto es, la designación en .libertad. por parte de la ciudadanía y mediante el ejercicio individual del voto de la representación política del poder.

Pensamos que el objeto de análisis escogido, la experiencia electoral gaditana en ambas fechas, queda justificado no solamente por razones de proximidad y familiaridad de la que escribe con dicho entorno, sino porque mantiene en sí mismo el interés de apreciar las transformaciones 
sufridas en la opinión política de sus ciudadanos desde la primera consulta en libertad efectuada en enero de 1869 y decantada en favor de la opción republicana hasta que, pasados más de veinte años, tengamos que explicar el triunfo electoral de candidaturas monárquicas en la ciudad.

Nuestras investigaciones ${ }^{1}$ acerca de la indiscutible convicción republicana que demuestran tener los gaditanos en las primeras elecciones celebradas bajo el sistema político demoliberal que abandera la coalición revolucionaria del «68* y el brusco cambio de orientación monárquica del mismo electorado en las siguientes consultas generales establecidas durante el Sexenio, nos ponen sobre la pista de considerar dudosas, en cuanto a los procedimientos empleados en ellas, a algunas de las convocatorias que hemos estudiado, poniendo en entredicho la limpieza que sin discusión solemos adjudicar a los comicios hijos del septembrismo. Sería conveniente, a la luz de las prácticas fraudulentas en este caso observadas, establecer un puente entre los modos electorales de la etapa isabelina, amparados en el sufragio censitario, y la conducta observada por los políticos restauracionistas, ya en su fase de voto restringido (hasta 1891), ya en la etapa que propiamente reconocemos como la más corrupta de toda nuestra historia demoliberal (1891-1931). Este puente, sin duda alguna, pasa por el período :impoluto" del Sexenio Democrático que, al menos, en el marco local que estudiamos e incluso en su etapa republicana de 1873 se muestra igualmente proclive al ensayo de procedimientos más o menos graves, más o menos picarescos para asegurar la victoria a un grupo político determinado interesado en el poder.

Las primeras consultas efectuadas en la ciudad tras el triunfo de "La Gloriosa" poseen fecha de enero de 1869 y una de ellas tiene por objeto designar a los representantes que por esta circunscripción tendrán la misión de intervenir en las Cortes Constituyentes ${ }^{2}$. Primeramente se habían celebrado las municipales que otorgaron una amplia victoria al sector político republicano de la ciudad que pasa a ocupar el Ayuntamiento, organismo que se va a revelar en un futuro cercano como la instancia más capacitada para manejar futuras elecciones. El censo oficial de electores,

(1) Nos referíamos a nuestra Tesis Doctoral que fue publicada con posterioridad a la celebración de este Congreso, Gloria Espigado Tocino, La Primera Repüblica en Cádiz, estructura social y comportamiento político durante 1873. Ed. Caja de Ahorros de San Fernando, Sevilla y Jerez, Cádiz, 1993.

(2) La provincia de Cádiz había sido dividida en dos circunscripciones electorales encabezadas por la capital, que englobaba al conjunto de pueblos de la Bahía,y por Jerez de la Frontera, a la que se le asignaba el resto. El recurso de dividir a las provincias con mayor número de habitantes era una manera de contrarrestar la predilección por el republicanismo que se les presumía en favor del conservadurismo de las provincias del centro, mucho menos pobladas. Artola, M., Partidos y programas políticos, (18081936), Aguilar, Madrid 1977, p.66. 
establecido desde esta cédula de poder local en las recientes municipales, pasa de 13.660 electores (varones mayores de 25 años como marcaba la Ley) a 14.133, ya que en la designación de diputados la tropa acuartelada en las diferentes poblaciones tenía derecho a participar en los comicios, como así consta en las Actas correspondientes ${ }^{3}$. De entusiasta se puede calificar la respuesta del electorado gaditano en esta ocasión, ya que fueron 9.605 votantes, casi el $68 \%$ del total, los que acudieron a las urnas ${ }^{4}$ $\mathrm{y}$, de igual modo, volvería a repetirse la victoria holgada de la candidatura republicana (conseguiría el $71^{\prime} 7 \%$ de los votos) sobre la oponente monárquica. Los candidatos de ésta última, integrantes de la coalición que unía al partido progresista y al unionista en el poder, fueron limpiamente vencidos en esta capital andaluza (las reclamaciones que recogen las Actas, tanto de las municipales como de las generales, no dan pie para sospechar fraude alguno), por los republicanos Manuel Francisco Paul y Picardo, pariente del también correligionario José Paul y Angulo y comerciante de destacadísima fortuna en la ciudad, Gumersindo de la Rosa y Martínez del Corro, también hijo de comerciantes gaditanos, lo mismo que el futuro jefe cantonal y también votado Fermín Salvochea y Alvarez y, por último, el cartagenero pero con cierta vinculación a esta ciudad Fernando Garrido, eminente representante de nuestro socialismo utópicos.

Pronto, la marcha de los acontecimientos en todo el país darán al traste con tanta ilusión republicana, cuyo triunfo en esta capital andaluza se ve diluido entre la amplia mayoría monárquica de los representantes elegidos para formar parte de las Constituyentes. El escamoteo de las principales reivindicaciones revolucionarias esgrimidas para conseguir el apoyo popular tras la acción emprendida el 18 de septiembre, la imposición de nuevos impuestos como el de "capitación" en sustitución de los odiados "consumos", o la simple restitución de éstos, la convocatoria de nuevas quintas a raíz del problema independentista antillano, la supresión de las juntas y de las milicias ciudadanas locales que velaban por la pureza y conservación de los principios programáticos pactados por el

(3) Actas de Elección de Diputados a Cortes, enero de 1869, Archivo Municipal de Cádiz (en adelante A.M.C.), Vols.4140/41/42.

(4) El indice de participación media que presenta Martínez Cuadrado, M., para esta consulta es del $70 \%$ en todo el país, calificándolo de excepcional, Elecciones y partidos políticos de España (1868-1936), Taurus, Madrid, 1969, p.82. Hay que añadir que los buenos resultados para los republicanos en Cádiz no se corresponden con el total de diputados conseguidos por el partido en el conjunto del Estado, tan sólo 69, Hennessy, C.A.M., La Republica Federal en España, Aguilar, Madrid, 1966, p.109.

(5) De todos ellos, Fermín Salvochea no llegaría a ser designado diputado al considerar la Comisión del Congreso encargada de dar el visto buenos a las Actas de elección que su condición de preso, motivada por su participación en el levantamiento ocurrido en la ciudad en diciembre pasado, le incapacitaba para ello. 
grupo conspirador de Ostende y, sobre todo, la proclamación monárquica hecha por el Gobierno Provisional (25 de octubre de 1868), ratificada en las Cortes (20 de Mayo de 1869) y en el texto constitucional promulgado en los primeros días de junio del mismo año, moviliza a los republicanos más activos que observan la inutilidad de la prosecución de la vía legal para conseguir sus objetivos. El levantamiento republicano del otoño, protagonizado por los principales dirigentes del partido, en la Sierra de esta provincia andaluza, una vez es aplastado por el Gobierno de Sagasta, supone la escusa perfecta para renovar, en sentido progubernamental, los ayuntamientos de varias localidades mezcladas con la sublevación, entre ellos el de la propia capital, de modo que, a partir de entonces, serán adoptadas desde este organismo las medidas necesarias para convertir por arte de magia en monárquica la profesión de fe republicana de principios de año.

En enero de 1870 , contando con la enorme ventaja de encontrarse desorganizada la oposición republicana en la ciudad, ya que sus componentes más activos se encuentran en el exilio y la prensa de este signo está obligada a permanecer muda, estos nuevos concejales, elegidos desde arriba, se disponen a "legitimar", por medio de unas elecciones, su posición en el Ayuntamiento de Cádiz. Sin embargo, el triunfo final conseguido en los comicios sólo puede ser comprendido si atendemos a las cosideraciones hechas más arriba y además añadimos a esto el comienzo de la manipulación electoral, que presagia los mejores momentos de los mecanismos fraudulentos de la Restauración. También en enero de ese año se elegía en la provincia de Cádiz el diputado a Cortes que faltaba para que la capital estuviese representada al completo en Madrid, pues, como dijimos, el Acta de diputado que había obtenido Fermín Salvochea el año anterior había sido rechazada por la Comisión correspondiente del Congreso y por la propia Cámara al dictar su incapacidad, tras su participación en el levantamiento de diciembre de $1868^{6}$. Las autoridades locales nombradas tras la sublevación republicana de octubre de 1869 reduce a 9.531 los posibles electores participantes. Aun así, Fermín Salvochea estuvo muy cerca de vencer en la capital a su oponente monárquico, Francisco Barca, que era además yerno y protegido del Alcalde designado por la autoridad militar de Cádiz, Juan Valverde, ratificado en su puesto en las últimas municipales celebradas a principios del mismo mes con la misma reducción interesada del censo. La participación llegó a ser esta vez de 5.555 votantes, el 58'62\% del electorado, debido a que, seguramente,la presencia de un candidato republicano

(6) Fernando de Puelles, Fermin Salvocbea, República y anarquia, Sevilla, 1984, pp.65-68. 
animaría a los votantes gaditanos. Tan sólo 276 votos separaron a los dos oponentes en Cádiz, si bien en el cómputo total de votos de la circunscripción la realidad es bien distinta, correspondiendo 16.717 votos al representante monárquico y únicamente 7.250 a Salvochea ${ }^{7}$. Las protestas republicanas incluidas en las Actas de elección hablan, además de esta reducción escandalosa del censo, del reparto indebido de la tropa entre los distintos colegios ${ }^{8}$, de la presión ejercida por la misma sobre los electores civiles, de la usurpación de papeletas, etc... Ante esto, la actitud del partido republicano, que veía como en la ciudad se afianzaban los unionistas y con ellos la candidatura al trono de su protegido, el Duque de Montpensier, no fue otra que la de continuar recomendando la abstención en adelante, en espera de tiempos mejores para el partido.

En Cádiz, el protagonismo que había proporcionado a la ciudad la acción de los republicanos el año anterior había dado paso a la tranquilidad y a la calma que se vivía en ausencia de revolucionarios como Salvochea. Como hemos visto, la labor del partido, en esta coyuntura, se limitaba a poner en evidencia los manejos electorales de los unionistas y a protestar por ello, manteniéndose en una actitud abstencionista frente a los comicios. Sólo la aparición, el 1 de octubre, de La República Federal Un'versal haciendo uso de un lenguaje más agresivo representa un revulsivo en'la vida lánguida que hasta ahora mantiene el partido en la capital provincial. El interés del rotativo se sigue centrando en la denuncia del fraude electoral persistente, acusando al gobernador civil de ser una pieza clave en el falseamiento del sufragio universal ${ }^{9}$. En otra ocasión, los esfuerzos van dirigidos a hacer un llamamiento a todo aquel que se encuentre injustificadamente privado del derecho del voto, recomendando lo comunique a las comisiones electorales del partido para que éstas, a su vez, efectúen la oportuna reclamación ${ }^{10}$, al mismo tiempo que se denuncia la forma 'en que se está confeccionando el nuevo padrón electoral:

"Un amigo...regala 10.000 duros al que le resucite en el padrón vecinal, si es que en Cádiz hay padrón...

"Nos dicen que faltarán 7.500 ó 8.000 electores en las próximas elecciones, si es que las hay, que lo dudo..11

(7) El resto de la circunscripción la formaban las poblaciones de Medina, Alcalá, Chiclana, Vejer, Conil, El Puerto de Santa María, Puerto Real, Rota y San Fernando.

(8) Según recogen las protestas de las Actas, la Ley no permitía que excediera en más de 10 el número de electores militares de una sección a otra. Actas para la Elección de un Diputado a Cortes, enero de 1870, A.M.C., Vol.4145.

(9) La Repuiblica Federal Universal, N³, de 4 de octubre de 1870.

(10) Ibidem., №7, de 8 de octubre de 1870.

(11) Ibidem. En Jerez parece que se recurre a los mismos manejos, Ibidem., No15, de 16 de octubre de 1870 . 
Tras la designación de Amadeo como definitivo monarca, la muerte inesperada en atentado de Prim deja expedita, dentro del partido progresista, la lucha por la jefatura que se disputarán, a partir de entonces, los acólitos de Sagasta y Ruiz Zorrilla. Se trata de una pugna por alcanzar el poder entre personalidades que, sin embargo, tendrá consecuencias políticas, debido a los apoyos tácticos buscados por cada uno de ellos en su empresa. Sagasta terminará fundiéndose con los unionistas acomodados con la nueva dinastía y, por su parte, Zorrilla confiará en los demócratas de Rivero y Martos, e incluso, tras la declaración de "benevolencia* hecha por Castelar en el mes de junio, juzgará posible contar con los republicanos ${ }^{12}$.

En 1871 se celebran en Cádiz tres consultas electorales en las que se va perfilando, progresivamente, el resquebrajamiento del partido en el gobierno en favor de los partidarios de Sagasta que se valen de una manipulación escandalosa de los comicios. En marzo tienen lugar las elecciones de diputados a Cortes, la elevación del número de electores hasta 7.858 (en las Provinciales pasadas solamente habían disfrutado de este derecho 5.741 ciudadanos) responde a la inclusión en el cuerpo electoral del ejército y no a una ampliación en el censo de los civiles. La designación de los diputados a Cortes recae sobre el impopular José González de la Vega, por el primer distrito urbano, y sobre uno de los principales protagonistas de la Revolución del ‘68*, Juan Bautista Topete, por el segundo distrito, como tributo al reciente maridaje entre unionistas y sagastinos. Protestas y algún que otro acto violento ante las mesas electorales son los incidentes registrados en las Actas que reflejan el descontento creciente del resto de los partidos ${ }^{13}$.

Volviendo al ejercicio electoral gaditano de ese año, los días 7,8 y 9 de diciembre asistimos a la renovación de los miembros del Municipio. Sin fuerza armada en el censo electoral, éste queda reducido a la cifra menor de todo el Sexenio: 5.118 electores, y, como es habitual, se vuelve a presentar, en solitario, el partido sagastino. El Diario de Câdiz, por estas fechas, recoge las protestas de los partidos progresista, radical y unionista. El recurso presentado por este último partido ante la Comisión de la Junta General de Escrutinio es desestimada ya que "se considera exagerada la cifra que se ha dado de excluidos. ${ }^{14}$.

(12) El 22 de junio, Castelar anunciaba en la Cámara que estaría dispuesto a ser benevolente. con un gobierno radical (así se llamaría el partido de Ruiz Zorrilla escindico del progresista). Esta manifestación provocaría la reacción en contra de los, desde entonces, llamados .intransigentes. que no estaban dispuestos a prestarse a semejante juego. Ambos términos se seguirán empleando más adelante y pasarán a designar el ala derecha y el ala izquierda del partido, respectivamente.

(13) Actas de Elección de Diputados a Cortes, marzo de 1871, A.M.C., Vol.4150.

(14) Actas de Elecciones para Concejales, diciembre de 1871, A.M.C., Vols.4154/55. denunciaban la pérdida de 1.900 electores desde las pasadas elecciones entre los que se encontraban nombres de adestacado prestigio y consideración en la ciudad. 
1872 se inicia con nuevas perspectivas electorales fijadas para el mes de abril con el objeto de que zorrillistas y sagastinos, una vez ha quedado definitivamente escindido el partido progresista, se disputen en las urnas la consecución del poder. El 27 de marzo se firma un manifiesto conjunto de protesta ante la manipulación del censo por parte de los que dirigen el Ayuntamiento. Se hacen responsables del escrito los conservadores, los radicales, los republicanos, los moderados e, incluso, los carlistas. Todos ellos, ante la imposibilidad de presentar una o varias candidaturas con porbabilidades de éxito, a causa de estas circunstancias que describen, optan por recomendar la abstención al electora do gaditano ${ }^{15}$.

Con la abdicación de Amadeo y la inauguración del régimen republicano el 11 de febrero de 1873 se abre la esperanza de recuperar la perdida representatividad en las elecciones. Para que esto ocurra hace falta contar con censos que contemplen en su verdadera dimensión todo el cuerpo electoral. En Cádiz esta labor fue facilitada por el Ayuntamiento nombrado por el Gobernador de la provincia el 8 de julio de 1872, que dejó en suspenso al que actuaba desde las elecciones municipales de diciembre de $1871^{16}$. Dicho Ayuntamiento, en el que figuraban radicales y republicanos, se encarga de confeccionar un censo electoral que sirva de apoyo en las primeras elecciones municipales republicanas, repartiéndose un total de 13.409 cédulas talonarias, con lo que se vuelve a los niveles de los primeros momentos de la Revolución Septembrina. El censo se verá ampliado, según el Artículo $4^{\circ}$ de la Ley de 11 de marzo de 1873, a los mayores de 21 años, cumpliéndose una vieja aspiración de los republicanos federales. Esta Ley, junto a la de 20 de agosto de 1870 , constituye la base legal que rige durante todo el período en materia electoral ${ }^{17}$. El capítulo $\mathrm{V}$ de la Ley de 1870 , dedicado a las disposiciones generales, preveía, por parte de la autoridad local y según el censo electoral establecido, la entrega a domicilio a cada uno de los electores de una cédula, garantía de su capacidad como elector, en la que debería

(15) Actas de Elecciones de Diputados a Cortes, Abril de 1872, A.M.C., Vol.4161. El censo se establece en 6.109 electores, fuerza armada incluida.

(16) Esta designación parece guardar relación con los desórdenes ocurridos en Cádiz a comienzos de julio y con otros semejantes acaecidos en la ciudad de Sevilla, historiados por Consuelo Pradilla Gordillo en -La política religiosa del Ayuntamiento sevillano durante la Primera República. en Actas del Primer Congreso de Historia de Andalucía, Ediciones de la Caja de Ahorros de Córdoba, 1979, Vol.II, p.31: .Cuando se proclamó la República regía en la ciudad un Ayuntamiento con mayoría de republicanos federales, que había sido nombrado por el gobernador en julio de 1872, después de un motín organizado por radicales y republicanos federales con objeto de protestar por la ilegalidad de las últimas elecciones.

(17) Tierno Galván, E., Leyes políticas españolas fundamentales (1808-1936), Tecnos, Madrid, 1975, pp.273-313. La Ley de 1870, junto a la de 26 de junio de 1890, constituyó el fundamento jurídico también de la experiencia electoral restauracionista. 
figurar su nombre y domicilio. En caso de extravío o de injusta omisión o denegación de la cédula por parte de los alcaldes de barrio, encargados de la distribución de las mismas, existía la posibilidad de reclamar ante la mesa de elecciones, previa identificación de la persona, una segunda cédula talonaria, duplicado de la anterior, que se encontraba en poder del presidente de la mesa. La Ley ofrecía suficientes garantías para la práctica del sufragio universal, que estas disposiciones se respetasen dependía, como hemos visto, de lo confiado que estuviese el poder instaurado respecto a lo que consideraba como electorado propio.

Tras el golpe Radical de 23 de abril de 1873 y la desvinculación de este partido de la suerte que pudiera correr la República todo quedaba pospuesto a que la escrupulosa legalidad de las fases ya previstas, elecciones generales para mayo y reunión de la Asamblea Constituyente resultante para primeros de junio, fuera abriendo camino a los objetivos republicanos. Sin embargo, el retraimiento de las fuerzas conservadoras y, fundamentalmente, la del partido radical, privaba a la facción republicana de un elemento esencial de cohesión política derivada de la existencia de un partido de oposición fuerte y capaz de afrontar el reto del poder. Las divisiones entre los mismos republicanos y la falta de consenso que arrastraban desde las últimas reuniones del partido harian que la lucha electoral se entablara entre ellos mismos, confundiendo a los votantes, crispando aún más las enemistades personales y debilitando a la propia República, ya que la marcha de ésta se confundía cada vez más con el rumbo que tomara el partido federal. En Cádiz, es perfectamente perceptible el clima de confrontación, que no siempre ha sido resaltado, y la investigación de la campaña electoral, la votación subsiguiente y las reclamaciones presentadas ante los resultados oficiales, arrojan luz sobre el ambiente de hostilidad política y personal que dismitifica la supuesta unidad republicana de la ciudad rendida a los pies del líder intransigente Fermín Salvochea. La lucha, cada vez más enconada, entre las dos facciones republicanas se dejó sentir abiertamente en las disputas para designar a los que serían candidatos del partido para las próximas elecciones a diputados, hasta el punto que, a cinco días vista para el inicio de los comicios, todavía no se contaba con los nombres definitivos. La influencia de Salvochea sería fundamental al despejar las dudas sobre quiénes consideraba dignos de encabezar la candidatura gaditana, publicando en La Soberanía Nacional sus simpatías por el general republicano Juan Contreras y el activista Diego Carrasco, en una actitud que le sería prontamente criticada por la op osición republicana de la ciudad. Para defender esta candidatura, La Soberania Nacional, el Ayuntamiento en pleno y el propio Salvochea pusieron en juego todo el peso de. su influencia y prestigio personal, en el caso del dirigente republicano, 
frente a sus oponentes que adoptarán a Gumersindo de La Rosa y a Arturo Fernández-Encinillas como a sus legítimos representantes. La confrontación se prometía dura y difícil entre ambos grupos de candidatos. Para comenzar, las mesas electorales, también designadas mediante sufragio, fueron ocupadas por los partidarios de Salvochea, lo que hacía temer al grupo oponente la posible manipulación de las elecciones, pese a las recomendaciones de limpieza que dictara $\mathrm{Pi}$ y Margall desde el Ministerio de la Gobernación ${ }^{18}$.

Entrando en el análisis de los aspectos técnicos de la votación, según lo dispuesto por la Ley electoral de 1870 podían ser electores los integrantes de las fuerzas del ejército y de la Armada, La Guardia Civil y los Carabineros. El pleno municipal encargado de su distribución los repartiría interesadamente entre aquellos barrios en los que se esperaba una respuesta más templada del electorado, confiando que el descontento del soldado, próntamente movilizado hacia el norte, hacia el frente carlista, se tradujera en apoyo al general Contreras que se presentaba en el distrito en el que debían votar. Si a los 18.819 electores oficiales restamos los 2.240 correspondientes a las Fuerzas Armadas nos queda el nuevo censo ectoral en 16.579 individuos, lo cual quiere decir que los nuevos 3.170 eran jóvenes en edades comprendidas entre los 21 y los 25 años con los que se ampliaba el cuerpo electoral según la disposición de 24 de marzo de ese mismo año que cumplía con una vieja aspiración republicana. La participación media resultante de los tres días que duró la votación supera ligeramente el $40 \%$ que Miguel Martínez Cuadrado asigna para el contexto nacional, el $41,2 \%$ del electorado, 7.764 varones mayores de 21 años ejercieron su derecho ${ }^{19}$.

Hablemos ahora de las candidaturas votadas. En el primer distrito la lucha fue reñida entre Juan Contreras, que hace suyos el 59'6\% de los votos, y Gumersindo de La Rosa que contó con el 39\% a su favor. En el segundo distrito electoral Diego Carrasco venció sin ninguna dificultad acaparando el $71^{\prime} 2 \%$ de todos los votos emitidos. Arturo Fernández-Encinillas, sin apenas relevancia, se tuvo que contentar con tan sólo el $12 \%$ de las urnas. Cádiz volvía a ratificar su apoyo al ala izquierda del partido republicano federal para que ocupase sus escaños en la Asamblea Constituyente. Sin embargo, un hecho crucial vino a enturbiar y a anular los efectos de esta victoria. Las Actas de las elecciones gaditanas fueron impugnadas ante la Comisión del Congreso que debía estudiar y sancionar la legalidad de éstas ${ }^{20}$. La responsabilidad de

(18) Boletin Ofícial de la Provincia de Cádiz, N¹04, de 5 de mayo de 1873.

(19) Martínez Cuadrado, M., Op. Cit., p.202.

(20) Actas de Elección del Congreso de Diputados, Legajo, 74, Archivo del Congreso de
Diputados. 
esta impugnación corre a cargo de los mismos compañeros republicanos de oposición. Entre los hechos más graves se citaba el apaleamiento e insultos de los electores, el voto consentido con papeletas de enfermos y ausentes, los impedimentos de entrada en los colegios a aquellos que portaban papeletas de la candidatura oponente y la destrucción de las mismas, la propaganda descarada del Alcalde, Fermín Salvochea, y sus colaboradores en favor de una determinada opción calificada de candidatura oficial, la utilización de los voluntarios, que repartían estas candidaturas y rasgaban aquellas papeletas que los electores llevaban a las urnas, como grupo armado de coerción sobre los votantes, etc. La demora continua para resolver el problema de las Actas pudo repercutir sobre una población ganada, cada vez más, por el escepticismo y la desgana, incidiendo en la acentuación del abstencionismo de la misma en las próximas consultas, al mismo tiempo que crecía el convencimiento intransigente de la inutilidad de la vía parlamentaria para conseguir sus objetivos.

El estallido cantonal y la guerra civil entre los republicanos, la derechización en manos de Salmerón y Castelar del régimen instaurado el 11 de febrero, ponen el contrapunto de una República que pretendió ser democrática y federal en un principio. El general Pavía, a comienzos de 1874, se encargaría de darle el golpe de gracia y, pasada la interinidad que marca la jefatura de Serrano al frente de una República unitaria y dictatorial, la Restauración borbónica en la persona de Alfonso XII, largamente anunciada, se convierte por fin en un hecho. Su principal valedor y dirigente del partido Conservador Liberal Dinástico, Antonio Cánovas del Castillo, es el verdadero artífice y creador del sistema político restauracionista que pone a prueba un largo período de inquietante estabilidad política, quizá la más larga de nuestra contemporaneidad por el momento, que abarca por lo menos medio siglo a caballo entre el XIX y nuestro actual siglo XX.

En cuanto al procedimiento o los precedimientos, mejor dicho, ensayados en tan largo período de vigencia institucional, éstos pasan por el breve espacio confiado a la seguridad que otorga a la élite en el poder el voto censitario y por la vuelta al sistema universal (Ley de 26 de junio de 1890) que permite la emisión del sufragio a todo español varón mayor de 25 años y en pleno disfrute de sus derechos políticos. No hay que insistir aquí, muchas monografías se han dedicado a ello, en que el retorno al demoliberalismo se efectúa no sin tomar las precauciones precisas por parte de la clase dirigente para no perder de las manos las riendas estatales, en una fase en el que el desarrollo de las tesis y el asociacionismo obreristas podían hacer peligrar su preeminencia política. Las corruptelas electorales que nos son de sobra conocidas a través de 
los trabajos de carácter general o local ${ }^{21}$ y de las que ya se hacían eco los "regeneradores* del momento, cuyo ejemplo más conocido será la denuncia que Joaquín Costa a través de su Oligarquía y Caciquismo hace de la imperiosa necesidad de controlar la pureza del procedimiento, han llevado a acuñar la expresión profusamente utilizada que insite en el divorcio que consagran estos mecanismos fraudulentos entre la España real y la España oficial de la época. En medio de tanta iniquidad, la vuelta al sufragio universal, legislado en 1890 y practicado al año siguiente, supuso, en opinión de algunos ${ }^{22}$, la esperanza de convertir al régimen de la Restauración en la verdadera expresión de la opinión política de todos aquellos votantes convocados nuevamente ante las urnas.

La práctica de entonces, con el mantenimiento, que no la creación ex novo, si nos atenemos a la experiencia del Cádiz Septembrino que ya hemos analizado, de todo tipo de corruptelas electorales aplicadas por todos aquellos que tenían algún tipo de participación en el procedimiento (no vamos a insistir aquí en la, de sobra conocida, red de mutua interdependencia que el encasillado establece entre el Ministerio de la Gobernación, los gobernadores civiles y los caciques y jefes de los partidos dinásticos en las distintas provincias), vino a dar la razón a los que, como contrapunto, no miraban con demasiada esperanza las supuestas nuevas perspectivas políticas que cabía esperar de la ampliación del electorado. Así se expresaba en Cádiz, el órgano oficial del segundo partido dinástico, el liberal-fusionista, que presidía Práxedes Mateo Sagasta, La Nueva Era:

*...solamente abusando de la influencia [quel proporciona la posesión del Gobierno, podrían emplearse ciertos procedimientos que mixtifican la voluntad del país. Bien sabemos que el sufragio universal no será ensayado en toda su pureza mientras que por parte de los encargados de cumplir y hacer cumplir la ley no haya verdadero interés en que así sea...

«Pero vendrán las exigencias de los comprendidos en el encasillado y de los caciques de campanario dando al traste con cuantas protestas de

(21) Son de agradecer los trabajos que abordan la cuestión desde la perspectiva local, única capaz de ofrecer los auténticos entresijos de la trama caciquil, como el de José $\mathrm{M}^{2}$ Barreda Fontes, Caciques y Electores. Ciudad Real durante la Restauración, (18761923), Instituto de Estudios Manchegos, Madrid, 1986.

(22) Dice Javier Tusell refiriéndose a la campaña de comienzos de 1891: Ante el ensayo del mismo, la totalidad de la prensa muestra la trascendencia del momento que se vive y el deseo de que se traduzca en un progreso efectivo de las costumbres ciudadanas. La simple existencia de este deseo indica, por supuesto, que se considera como factible la posibilidad de que el sufragio universal, por su propia virtud regeneradora, suponga la independización del electorado (...) Pero no es únicamente la prensa quien concede una especialísima importancia al nuevos sistema electoral, sino que, además, aparecen testimonios de que todo el país copnfía en que el sufragio universal transformará de una manera radical y definitiva la vida política del país. Tusell, J., Oligarquía.y Caciquismo en Andalucia (1890-1923), Planeta, Barcelona, 1976, pp. 525 y 526. 
sinceridad ha consignado la prensa oficiosa: las probabilidades de la derrota les hará emplear toda clase de recursos para ejercer presión sobre los electores y dislocar la emisión del sufragio, y las urnas darán un contingente de diputados al gobierno para que pueda presentarse con escrupulosa mayoría ante la representación nacional. Ese será el resultado material que todos los que no comulgamos en la grey conservadora tenemos previsto ${ }^{23}$.

Muy al contrario, aquellos que esperaban anticipadamente confiados la victoria del partido Conservador canovista y que se erigían en sus portavoces, como ocurre con el diario gaditano La Palma, se esforzaban por hacer ver al electorado la trascendencia del momento e insitian en la oportunidad que se otorgaba a las opciones antidinásticas para concurrir de forma legal y pacífica a medir "justamente" sus fuerzas con el resto de los partidos que apoyaban al sistema:

-...las elecciones generales de 1891 serán sin la menor duda un hecho importantísimo... y aún los prelados, que hasta aquí se abstuvieron de mezclarse en ese movimiento, insertan en los Boletines diocesanos circulares trazando reglas a que el clero y los seglares deben, a su juicio, atenerse...

-...las elecciones de 1891 tendrán, entre otros caracteres, el de haber hecho patente la postración y descrédito de la protesta revolucionaria ${ }^{24}$.

En cuanto a los candidatos que los partidos en liza presentaban en la circunscripción gaditana, los conservadores, seguros de su victoria, traían a un *cunero", es decir, a un miembro del partido sin raíces y vínculos personales o políticos con la circunscripción por la que concurre, Eduardo Garrido Estrada, junto al que sería compañero de candidatura, Joaquín María Aranda (el más votado en las listas de Cádiz). Los liberales confiaban en el prestigio y popularidad que el jefe del partido en la capital provincial había conseguido a través de su gestión como Alcalde de la misma. Al lado del comerciante Enrique del Toro y Quartillers participaba en los comicios el menos conocido Ramón Auñón y Villalón, mientras que en los restantes distritos provinciales los liberales esperaban arrancar un resultado positivo con miembros de la nobleza como Juan Manuel Sánchez y Gutiérrez de Castro (Duque de Almodovar del Río) por Jerez y Alfonso Alvarez de Toledo (Conde de Niebla) por Medina. Los republicanos que, en principio, podían tener confianza en una demostración sincera de republicanismo por parte de una de las ciudades que en un pasado no tan lejano se había mostrado proclive hacia esta forma de gobierno, se enfrentaban con el obstáculo de seguir divididos, tanto a nivel local como nacional, más aún que antes, en multiples opciones de muy difícil compaginación ideológica. Por un lado los posibilistas castelarinos se habían acomodado en los

(23) La Nueva Era. Organo del partido Liberal Dinástico, N22969, de 15 de enero de 1891. (24) La Palma, №52.530, de 18 de enero de 1891. 
estrechos márgenes legales que la Restauración les había ofrecido. Los antiguos progresistas de Ruiz Zorrilla, en cambio, no se resignaban al entendimiento pacífico con los partidos dinásticos y confiaban, una y otra vez, en el, hasta ahora, estéril recurso de la fuerza, del pronunciamiento, para volver a instaurar la república. Una república que si bien se entiende unitaria en ambas facciones, así como en la que encabeza el antiguo presidente republicano Nicolás Salmerón, es irreconciliablemente federal en el grupo que comanda Don Francisco Pi y Margall y federal con el matiz de organicista entre los acólitos de Figueras. Sin embargo, pese a la división observada, la oportunidad de obtener representación parlamentaria conducirá al pacto de algunos de estos grupos en determinadas circunscripciones con esperanza de éxito. Este es el caso de Cádiz, donde José Marenco Gualter, hijo de comerciante gaditano, seguidor hasta la fecha del tormentoso grupo zorrillista acepta el juego electoral compartiendo candidatura con un federal de amplio reconocimiento en la provincia por ser natural de ella y haber ejercido un ministerio, el de Fomento, en la pasada República, nos referimos al jerezano Eduardo Benot.

Sin embargo, pese a este despliegue de candidatos, para algunos, la suerte está echada de antemano. De esta opinión eran los liberales de $\mathrm{La}$ Nueva Era:

*Los candidatos ministeriales que figuran en el encasillado se ha repartido por los distritos, más que para conquistar los votos de los electores, para correr las órdenes que cumplirán y harán cumplir puntualmente los representantes del gobierno, con objeto de que los amigos llamados sean también elegidos:25.

Con estas perspectivas es lógico pensar que la campaña electoral se cifrase, antes que en la defensa de programas completos de actuación para una vez se haya conseguido el poder o en la discriminación ideológica del pensamiento político que inspira a cada opción que entra en lucha, en la insistente puntualización en torno a la honradez de los candidatos presentados, al mismo tiempo que se erigen a los adversarios más peligrosos en los campeones de la corrupción más desenfrenada. Así, en esta personalización de la campaña, el partido liberal gaditano tendrá su mejor carta de presentación ante la opinión pública en la confianza que Enrique del Toro se haya podido ganar entre sus conciudadanos en los años que estuvo vinculado al municipio de la localidad:

- Decíamos ayer que la sola enumeración de los nombres de las dignas personas designadas por el partido liberal para candidatos en las próximas elecciones, era más que suficiente para que el cuerpo electoral de esta circunscripción, corriese lleno de fe a depositar sus votos en favor

(25) La Nueva Era, №2.972, de 18 de enero de 1891. 
de los que por su pasado y su presente inspiran a todos la más firme seguridad de que aquellos, investidos con el carácter de representantes de esta región en las Cortes han de ser valientes campeones, constantes defensores de los intereses generales de la misma ${ }^{26}$.

Paralelamente, advertían a la masa electoral más significativa, los trabajadores, de no dejarse engañar ni comprar por el juego sucio y las ofertas fraudulentas de los conservadores:

-El que se vende por un pedazo de pan o por un puñado de oro, no merece otra cosa que la cadena de la esclavitud. Rechazad todos la imposición de vuestros patronos. Recordad que con el triunfo de los conservadores volveréis a recobrar las cadenas que rompió el partido liberal y que estas serán las últimas elecciones por sufragio universal que se celebren si los liberales somos derrotados....27.

El domingo, día 1 de febrero, tiene lugar la votación permitiendo emitir el sufragio a 10.131 gaditanos varones mayores de 25 años. Como se puede apreciar, el cómputo de electores no deja sospechar las purgas extremas del período central, monárquico, del Sexenio, pero tampoco resiste la comparación con las que poseen mayores visos de fiabilidad, aquellas que se celebraron en enero de 1869 (con 14.133 electores) y las republicanas de mayo de 1873 (con 18.819 electores). Si consideramos que la población de Cádiz en el último cuarto de siglo no varía sensiblemente, según los datos suministrados por los diferentes censos nacionales (1877, 65.028 habitantes; $1887,62.531$ y 1900, 69.382), es lógico pensar que el cuerpo electoral fijado para el sufragio universal de 1891 ha sido revisado con sumo cuidado y atención por parte de los que no quieren llevarse ninguna sorpresa ${ }^{28}$. De nuevo, la inclinación prorrepublicana que se le reconocen a casi todas las capitales de importancia del país se ve conjurada con la inclusión en cada uno de estos distritos electorales de poblaciones más dóciles de manejar y con cuyo concurso se puede hacer variar la decisión antidinástica de un núcleo importante. En el caso de esta capital andaluza, a las 21 secciones en que se encuentra dividida hay que sumar las 11 que componen la vecina población de San Fernando, las 6 de Chiclana y las 3 de Conil, que hacen un total de 19392 electores posibles, casi el doble que se adjudica a la capital provincial:

(26) Ibidem., №2.981, de 29 de enero de 1891.

(27) Ibidem., №2.983, de 31 de enero de 1891.

(28) Miguel Artola advierte que el aumento demográfico de algunas capitales que se produce durante toda la etapa restauracionista como resultado de su desarrollo material y urbano no se tradujo en una nueva relación entre población y representación política concedida, que apenas tendrá alguna variación en todos esos años. Artola, M., Op.Cit., p.67. 


$\begin{array}{lcccc} & \text { ELECTORES } & \text { VOTANTES } & \text { PARTICIPACION MEDIA } \\ \text { CADIZ } & 10.131 & 4.941 & 48^{\prime} 7 \% & \\ \text { SAN FERNANDO } & 5.348 & 2.811 & 52^{\prime} 5 \% & \\ \text { CHICLANA } & 2.625 & 1.722 & 65^{\prime} 6 \% & \\ \text { CONIL } & 1.288 & 907 & 70^{\prime} 4 \% & \\ \text { TOTAL } & 19.3920 & 10.381 & 533^{\prime} 5 \% & 29\end{array}$

Lo primero que sorprende, al apreciar la participación porcentual del electorado en las diferentes poblaciones, es que la mayor abstención se registra en Cádiz capital (con la inmovilización de más de la mitad de su electorado) mientras que el concurso va aumentando a medida que decrece la entidad demográfica de la población en cuestión (el retraimiento en Conil es tan sólo de un 30\%). Er cuanto a la distribución del voto entre las tres candidaturas con mayores probabilidades de éxito, también resulta sospechosa (ya lo advertirían los liberales) la moderación del voto republicano en la capital, la victoria indiscutible de esta opción en la contigua San Fernando, así como la superación del voto republicano por encima del liberal en la localidad de Chiclana, dándose por contentos, los liberales, únicamente con el 40 '5\% arrancado en Conil que los sitúan preeminentemente en aquella población. La derrota, en todo caso, para éstos últimos, estaría provocada por el exclusivismo* de los republicanos que, de haber aceptado una alianza electoral, hubiesen propiciado la derrota de la lista conservadora ${ }^{30}$.

$\begin{array}{lccc} & \text { VOTOS } & \text { PORCENTAJE } & \text { DIPUTADOS } \\ \text { CONSERVADORES } & 4.743 & 446 \% & 2 \\ \text { REPUBLICANOS } & 3.086 & 29 \% & 1 \\ \text { LIBERALES } & 2.790 & 262 \% & 0{ }^{31}\end{array}$
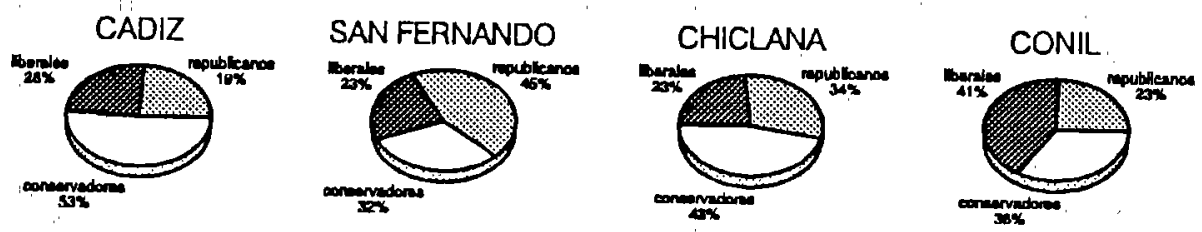

(29) Actas de Elecciones de Diputados a Cortes, febrero de 1891, A.M.C., Vol.6320.

(30) El resultado de San Fernando tan sólo lo pueden achacar a la connivencia entre conservadores y republicanos para desbancar a los liberales de la posición preeminente que parecían gozar desde las pasadas provinciales: :Una población oficial en su mayoría, acusa el resultado de dar un exceso de 600 y pico de votos a los republicanos sobre los conservadores y sobre nuestros amigos, y esto es tanto más inexplicable cuanto que no hace dos meses a esa misma cifra alcanzó la mayoría que los liberales alcanzamos", La Nueva Era, №2.985, de 3 de febrero de 1891.

(31) Diario de Sesiones del Congreso de Diputados, 1891, Vol.I, pp.6-12. 
En cuanto a la denuncia de irregularidades cometidas durante las elecciones, si bien las Actas conservadas en el Archivo Municipal gaditano no son protestadas, salvo en la $3^{z}$ sección correspondiente al barrio de Cortes, sin que prosperase dicha reclamación ${ }^{32}$, los hechos más escandalosos se van a dar fuera de esta circunscripción electoral, en la contigua población de El Puerto de Santa María, y la relevancia del personaje afectado, Isaac Peral, hace que merezca que nos refiramos a los hechos aunque sea con brevedad. El ilustre inventor del submarino decidió presentarse a los comicios de 1891 en esta provincia después que sus experimentos con el sumergible en estas aguas fueran considerados por las autoridades de Madrid como un auténtico fracaso ${ }^{33}$. La orden recibida desde el Ministerio de Marina para que hiciera entrega del submarino fue contestada inmediatamente por Peral con la petición de licencia absoluta de sus obligaciones con la Armada, a fin de poder defender de forma independiente y libre la base científica de sus trabajos ${ }^{34}$. Dolido por tanta incomprensión, es posible que pensara que una buena forma de vindicar su actuación en todo este asunto fuese la presentación de su candidatura para las elecciones de principios de año, con el propósito de contar con el foro de las Cortes para explicar a la Nación los atropellos injustos de que había sido objeto. Javier Tusell confunde su filiación con el republicanismo, aunque se extraña que, dándose esta circunstancia, aceptase en la campaña relaciones públicas con el clero portuense ${ }^{35}$. La verdad es que varios notables de aquella población lo erigieron en candidato independiente, mas, dado el entusiasmo con el que lo defiende La Nueva Era y por indicación expresa del mismo rotativo, sabemos que es el partido liberal el que apoya su elección ${ }^{36}$. El contrincante que el encasillado conservador dispone se enfrente al popular Isaac Peral es nada más y nada menos que un "cunero" de excepción, el hijo del Ministro de Marina que ha desautorizado a Peral, Francisco Javier Beranguer Carrera. El resultado final, si bien es ampliamente favorable

(32) Un estudio de los manejos fraudulentos tipificados en la legislación electoral española puede efectuarse a través de Esteban Mestre, Los Delitc: Electorales en España, (18121936), Editora Nacional, Madrid, 1977.

(33) Los diferentes ensayos que se llevaron a cabo con la colaboración de la marinería de La Carraca han sido glosados recientemente por Joaquín María Piñeiro Blanca en, -Isaac Peral y la navegación submarina a través de la prensa gaditana (1887-1891)., en Trocadero, №2, Servicio de Publicaciones de la Universidad de Cádiz, 1989, pp.231-237.

(34) Carta de Isaac Peral a Rafael Calzada, firmada en San Fernando el 25 de noviembre de 1890 y publicada por La Nueva Era, N22.987, de 5 de febrero de 1891.

(35) Tusell, J., Op.Cit., p.376.

(36) La Nueva Era, №2,977, de 24 de enero de 1891: .El partido fusionista apoyará también, obedeciendo instrucciones superiores, la candidatura independiente por El Puerto de Santa María del Señor Isaac Peral y Caballero. 
para el primero en la localidad portuense (1780 votos contra 556) aun contando con los manejos de todo tipo denunciados por la prensa liberal, es adverso en el resto de los pueblos que componen la circunscripción, por lo que, a pesar de las protestas habidas, será el candidato conservador el que consiga el triunfo final ${ }^{37}$.

Recapitulando todo lo dicho hasta aquí, hemos pretendido ilustrar con la descripción de las circunstancias más significativas que rodean dos momentos políticos tradicionalmente valorados de forma distinta en nuestro país la presencia de actitudes y comportamientos muy semejantes entre ambos períodos en lo que a materia electoral se refiere, por lo que estamos en condiciones de concluir que los manejos electorales que son normalmente aceptados en el falseamiento del sufragio restauracionista hunde sus raíces en los ensayos demoliberales del Sexenio, incluso en su etapa republicana, al menos por lo que respecta a la capital andaluza que analizamos.

$\begin{array}{lccccc}\text { (37) } & \text { EL PUERTO } & \text { ROTA } & \text { PUERTO REAL } & \text { ESPERA } & \text { TOTAL } \\ \text { BERANGUER } & 556 & 1.546 & 911 & 330 & 3.243 \\ \text { PERAL } & 1.780 & 303 & 403 & 25 & 2.511\end{array}$

La Palma, No52.546, de 3 de febrero de 1891 . 